\title{
Evolutionary, epidemiological, demographical, and geographical dissection of porcine bocavirus in China and America
}

\author{
Qiangzhe Zhang a, 1 , Caihong Zhang ${ }^{\mathrm{a}, 1}$, Mengxu Gao $^{\mathrm{d}}$, Xianzhi He ${ }^{\mathrm{b}}$, Yinghua Diao ${ }^{\mathrm{a}}$, \\ Sagar M. Goyal ${ }^{\mathrm{c}}$, Sunil K. Mor ${ }^{\mathrm{c}}$, Jinhai Huang ${ }^{\mathrm{b}, *}$ \\ a College of Pharmacy, State Key Laboratory of Medicinal Chemical Biology and Life Science Laboratory, Nankai University, Tianjin 300071, China \\ b School of Life Science, Tianjin University, Tianjin 300072, China \\ c College of Veterinary Medicine, Minnesota University, Saint Paul, MN 50018, USA \\ d State Key Laboratory of Resources and Environmental Information System, Institute of Geographic Sciences and Natural Resources Research, \\ Chinese Academy of Sciences, Beijing 100101, China
}

\section{A R T I C L E I N F O}

\section{Article history:}

Received 7 August 2014

Received in revised form

24 September 2014

Accepted 25 September 2014

Available online 5 October 2014

\section{Keywords:}

Porcine bocavirus

Phylogenetic analysis

Epidemiological investigation

Geographical dissection

\begin{abstract}
A B S T R A C T
Porcine bocavirus was first discovered in Swedish pigs with post-weaning multisystemic wasting syndrome (PMWS) in 2009. Many efforts have been implemented to investigate the porcine bocavirus, but it remains enigmatic. In the current study, we utilized data from both China and the USA. The China-derived data included 403 pig samples collected from five provinces, 122 gene sequences from the GenBank database, and 637 old porcine bocavirus (PBoV) cases. The USA-derived data comprised 181 pig samples from 18 states, 39 new gene sequences, and 85 new emerging cases. First, we executed a comprehensive analysis of the disease's prevalence, phylogenetics, evolutionary distances, mutation network, geographical distribution, occurrence frequency, and phylogeographical estimation in both China and the USA. The results showed that the positive rates of $\mathrm{PBoV}(42.0 \%, 76 / 181)$ in American samples were significantly higher than those $(11.4 \%, 46 / 403)$ in the Chinese samples. All PBoV cases from these countries can be divided into six groups: PBoV1 (group 1), PBoV2 (group 2), PBoV3C (group 3), PBoV5 (group 4), PBoV3/4 (group 5), and PBoV6V7V (group 6). PBoV1 and PBoV2 were epidemic strains from 2006 to 2011 in China, whereas the PBoV3 subtypes were epidemic from 2010 to 2012 in China and the USA. At present, PBoV3C (group 3), PBoV5 (group 4), and PBoV3/4 (group 5) are epidemic viruses and co-exist in China and the USA. The geographical distribution of PBoV mainly lies in the east and south coastal areas of China and the central states of the USA. Jiangsu Province and the state of Minnesota were the centers of high occurrence frequency of PBoV with six outbreaks. The old PBoV cases involved 14 provinces and regions of China and North Carolina in the USA, whereas the new emerging cases involved five provinces in China and 13 states in the USA, of which two provinces and 12 states reported for the first time that piglets were infected by PBoV. Hong Kong, Hebei, and Jiangsu Provinces and the states of Minnesota and North Carolina were possibly geographical origins of PBoV in China and America, respectively. These data can help us systematically understand porcine bocavirus in China and America and find effective strategies for its treatment.
\end{abstract}

(c) 2014 Elsevier B.V. All rights reserved.

\section{Introduction}

Bocavirus is a newly classified genus of the family Parvoviridae and includes bovine parvovirus (BPV)(Chen et al., 1986; Blomstrom

\footnotetext{
* Corresponding author at: School of Life science, Tianjin University, No. 92, Weijin road, Nankai District, Tianjin 300072, China. Tel.: +86 228740 2171; fax: +86228740 2171

E-mail address: jinhaih@tju.edu.cn (J. Huang).

1 These authors contributed equally to this work.
}

et al., 2013), minute virus of canines (MVC) (Binn et al., 1970), porcine bocavirus (PBoV) (Blomstrom et al., 2009; Choi et al., 2013), gorilla bocavirus (GBoV) (Kapoor et al., 2010), human bocavirus (HBoV) (Allander et al., 2005), and California sea lion bocavirus (CslBoV) (Li et al., 2011). In 2009, the PBoV-like virus was first discovered in Sweden pigs with post-weaning, multisystemic wasting syndrome (PMWS) using random amplification and large-scale sequencing technology (Blomstrom et al., 2009; Cadar et al., 2011; Li et al., 2012b). Soon after, Chinese scientists discovered the nearly full-length genome sequences of PBoV (HM053693, HM053694, and HQ223038) (Cheng et al., 2010; Zeng et al., 2011), which have 
Table 1

Prevalence of PBoV detected by PCR assay in different provinces of China.

\begin{tabular}{|c|c|c|c|}
\hline Provinces & Samples & $\begin{array}{l}\text { No. of positive samples/No. } \\
\text { of tested samples (\%) }\end{array}$ & Total positive/total tested (\%) \\
\hline \multirow[t]{2}{*}{ Henan } & ILN & $9 / 60(45.0)$ & \\
\hline & SLN & $2 / 40(0.0)$ & $11 / 100(11.0)$ \\
\hline \multirow[t]{2}{*}{ Shandong } & ILN & $15 / 23(65.2)$ & \\
\hline & SLN & $3 / 20(15.0)$ & $18 / 43(34.9)$ \\
\hline \multirow[t]{2}{*}{ Liaoning } & ILN & $4 / 20(20.0)$ & \\
\hline & SLN & $0 / 20(0.0)$ & $4 / 20(10.0)$ \\
\hline \multirow[t]{4}{*}{ Hebei } & Kidney & $0 / 3(0.0)$ & \\
\hline & Spleen & $11 / 53(20.8)$ & \\
\hline & Liver & $0 / 6(0.0)$ & \\
\hline & Lung & $0 / 8(0.0)$ & $11 / 70(15.7)$ \\
\hline \multirow[t]{3}{*}{ Tianjin } & Tonsil (A) & $1 / 20(5.0 \%)$ & \\
\hline & Tonsil (B) & $1 / 130(0.77)$ & $2 / 150(1.3)$ \\
\hline & Total & $46 / 403(11.4)$ & $46 / 403(11.4)$ \\
\hline
\end{tabular}

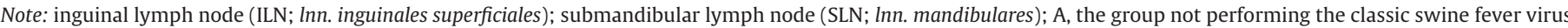
(CSFV) eradication program; $\mathrm{B}$, the group performing the classic swine fever virus (CSFV) eradication program.

a highly conserved alternative splice site and a putative secretory phospholipase A2 (sPLA2) motif in the NS1 and VP1 genes, respectively (Cheng et al., 2010; Zeng et al., 2011). PBoV has a much higher infection rate in diseased pigs than in healthy pigs, and post-weaning piglets are often co-infected with PCV2, PRRSV and PTTV2, which had a significantly higher prevalence in the PBoVpositive samples than that in the PBoV-negative samples (Zhai et al., 2010). The diseased weanling pigs showed severe lesions of the viscera, such as blood spots in the lung and liver, infarcts in the spleen and the kidney, and enlarged lymph nodes (Zhai et al., 2010). These results indicate that PBoV may be an important agent for PMWS of weanling piglets. PBoV sequences are traditionally classified into more than five genotypes, including PBoV1, PBoV2, PBoV3, PBoV4, PBoV5, PBoV3C, PBoV-6V, and PBoV-7V (Cheng et al., 2010; Lau et al., 2011; Shan et al., 2011a; Li et al., 2012a; Jiang et al., 2013). PBoV1 and PBoV2 were identified in the Jiangsu, Shanghai, Shandong, Anhui, Hebei, Henan, and Guizhou Provinces of China (Cheng et al., 2010; Shan et al., 2011a). Sequence analysis indicated that a 2-kb central region of PBoV1-H18 (HQ291308) had high homology to the known Swedish PBoV (PBoV-like; FJ872544) (Shan et al., 2011a), whereas PBoV2-A6 (HQ291309) was very similar to the PBoV1 and PBoV2 (HM053693, HM053694) genomes from China that were described in 2010 (Cheng et al., 2010). The complete genomes of PBoV3 and PBoV4 were identified and sequenced from fecal and nasopharyngeal specimens from porcines in Hong Kong (Lau et al., 2011). Evolutionary analysis suggested that they were distantly related to other PBoVs, forming a distinct cluster. Another novel porcine bocavirus, PBoV3C (JN681175), isolated from the Hebei Province, phylogenetically exhibited a distinctive set of sequence characteristics compared with other PBoVs (Yang et al., 2012). PBoV5, with 48.7-86.3\% homology to other PBoVs, was discovered and identified in clinical piglet stool samples from a farm in China (Li et al., 2012a). Phylogenetic analysis indicated that PBoV-6V and PBoV-7V, including a partial NP1 gene and the complete VP1 gene, formed a separate cluster from the other porcine bocaviruses (Cheng et al., 2010). Although we submitted these PBoV sequences to the GenBank database, only two complete genomes have been reported in America, and these were more distantly related to the partial $6 \mathrm{~V}$ and $7 \mathrm{~V}$ genomes from China (Shan et al., 2011b). Scientists have made many efforts to analyze the molecular and phylogenetic characteristics of PBoVs; however, the evolutionary characterization and the transmission possibility of porcine bocavirus in China and America remain unclear.

In the current study, we collected 403 and 203 porcine tissue samples and newly amplified 20 and 39 partial NS1 gene sequences of PBoV from China and America, respectively. Combined with the submitted PBoV sequences in the GenBank database, we systematically analyzed the phylogenetics, evolutionary distance, mutant network, and transmission possibility for 122 Chinese and 39 American PBoV sequences and found that the emerging PBoVs were concentrated on the east and south coastal areas of China and the central states of the USA. Phylogenetic and mutation network analyses indicated that all PBoV sequences were divided into five groups according to the evolutionary distance of each cluster; however, groups 1 and 2 consisted entirely of Chinese PBoV sequences. The structure of the evolutionary tree topology of ancestor sequences from mutation network analysis was similar to that of the PBoV NS1 gene and genome sequences. Furthermore, phylogeographical estimation suggested that the transmission possibility of PBoV is mainly from Jiangsu, Hebei, and Hong Kong to other provinces in China and from Minnesota and North Carolina to other states in America. These data can help us systematically understand the evolution and transmission possibility of porcine bocavirus in China and America and to find effective strategies for its treatment.

\section{Materials and methods}

\subsection{Sample collection, $P C R$, and sequencing of porcine bocavirus}

We collected 403 pig samples from five provinces in China and 181 pig samples from 18 states in the USA (Table 1). DNA was extracted from all of the samples using the Qiagen DNeasy blood and tissue kit (Qiagen, Valencia, CA, USA). The Qiagen HotStar Taq master mix kit (Qiagen, Valencia, CA, USA) was used for PCR with specific primers for the PBoV NS1 gene (PBoV-F: 5'-ACAGGCAGCCGATCACTCACTAT-3' and PBoV-R: 5'CTCGTTCCTCCCATCA GACACTT-3'). We sequenced 20 and 37 PCR products of $\mathrm{PBoV}$ samples from China and America, respectively. Fifty-one sequences have been submitted to GenBank (JX885585, JX944649-JX944667, KC514531-KC514561), and six sequences still remain unsubmitted.

\subsection{PBoV sequence datasets}

All PBoV sequences, including full- and partial-length genomes and genes, were retrieved from GenBank in July 2013. In addition to our new sequence data, there are 122 and $39 \mathrm{PBoV}$ sequences from China and America, respectively. The sequences from China include 12 complete or nearly complete genome sequences that encode the complete NS1, NP1, and VP1/2 genes, our 20 new sequences, and 90 partial gene sequences in GenBank. The American sequences include two complete genomes, our 31 new sequences, and six unsubmitted sequences. After filtering the redundant sequences, the remaining total 159 sequences included 14 complete or nearly 
complete genomes, 88 old partial genes, and 57 new partial genes involved in the following analyses.

\subsection{PBoV infection data}

PBoV information is often rare and incomplete. We collected the most reliable information from the sequence records, which include the site and date of virus occurrence, the host and subtype of virus infection, and the length and coding gene of the nucleotide sequences. In addition, we also collated the information regarding PBoV from published scholarly articles. Furthermore, we statistically tracked the outbreak frequency, the original marked virus subtype, and the number of cases of emerging PBoV in each Chinese province and American state using the ArcGIS geographic information system software (version 9.2; ESRI); in total, our system includes 637 Chinese and 85 American treated cases.

\subsection{Phylogenetic analysis}

The sequences were aligned using the CLUSTAL W algorithm (Larkin et al., 2007). Subsequently, we constructed a phylogenetic tree by the neighbor-joining and the maximum-likelihood methods. The nucleotide substitution model was selected using the Kimura 2-parameter or the Maximum Composite Likelihood in MEGA version 5.22 (Tamura et al., 2011). The tree reliabilities were tested with 1000 bootstrap replicates to yield a majority consensus tree.

\subsection{Evolutionary distance analysis}

To determine the nucleotide distances between and within groups in order to indicate the subtype demarcations, the average pairwise distances between and within the groups identified in the phylogenetic analysis were calculated with MEGA5 using the Kimura 2-parameter model (Tamura et al., 2011). The variance estimation was tested with 1000 bootstrap replicates. For each delimited subtype, the average distances between the groups were more than twice or nearly twice the average distance within the groups.

\subsection{Mutation network analysis}

We aligned the chosen sequences using CLUSTAL W2 (Larkin et al., 2007), deleted the identical nucleotide bases and edited these sequences, which were saved manually as rdf files. Mutation networks with different time nodes were constructed using the median-joining method in NETWORK version 4.611 (http://www.fluxus-technology.com/) (Bandelt et al., 1999). Finally, we combined the phylogenetic and alignment results and the network analysis to select target sequences for deducing ancestor sequences and grouping the subsets.

\subsection{Phylogeographical analysis}

Because the branching structure of the virus phylogenetic tree can provide a unique insight into its temporal and spatial dynamics (Holmes, 2004), the transmission possibility was inferred based on the phylogenetic tree using NS1 gene reconstruction with MEGA5.22 and information on the location and time of isolation for each PBoV. First, the sequences of the subtrees were extracted from the NJ tree using MEGA5.22. Second, combining the location and time of isolation for each strain, the ancestral locations of PBoV for the subtrees were estimated based on a maximum parsimony criterion. The ancestral location was evaluated for reliability with 1000 bootstraps.
Table 2

Prevalence of PBoV detected by PCR assay in different states of America.

\begin{tabular}{|c|c|c|c|}
\hline \multirow[t]{2}{*}{ States } & \multicolumn{2}{|c|}{$\begin{array}{l}\text { No. of positive samples/No. of } \\
\text { tested samples (\%) }\end{array}$} & \multirow{2}{*}{$\begin{array}{l}\text { Total } \\
\text { positive/total } \\
\text { tested (\%) }\end{array}$} \\
\hline & Lung & Feces & \\
\hline Arizona & $0 / 1(0.0)$ & $1 / 1(0.0)$ & $1 / 2(0.0)$ \\
\hline Arkansas & $2 / 4(50.0)$ & $3 / 8(37.5)$ & $5 / 12(41.7)$ \\
\hline Colorado & $0 / 0(0.0)$ & $3 / 10(30.0)$ & $3 / 10(30.0)$ \\
\hline Illinois & $2 / 4(50.0)$ & $7 / 8(87.5)$ & $9 / 12(75.0)$ \\
\hline Iowa & $1 / 2(50.0)$ & $5 / 6(83.3)$ & $6 / 8(75.0)$ \\
\hline Kansas & $0 / 0(0.0)$ & $0 / 1(0.0)$ & $0 / 1(0.0)$ \\
\hline Minnesota & $9 / 41(22.0)$ & $21 / 42(50.0)$ & $30 / 83(36.1)$ \\
\hline Missouri & $0 / 0(0.0)$ & $3 / 7(42.9)$ & $3 / 7(42.9)$ \\
\hline Michigan & $0 / 0(0.0)$ & $0 / 1(0.0)$ & $0 / 1(0.0)$ \\
\hline Nebraska & $0 / 0(0.0)$ & $4 / 5(80.0)$ & $4 / 5(80.0)$ \\
\hline North Carolina & $0 / 0(0.0)$ & $3 / 5(60.0)$ & $3 / 5(60.0)$ \\
\hline Ohio & $0 / 0(0.0)$ & $0 / 1(0.0)$ & $0 / 1(0.0)$ \\
\hline Oklahoma & $1 / 2(50.0)$ & $3 / 20(15.0)$ & $4 / 22(18.2)$ \\
\hline Pennsylvania & $0 / 0(0.0)$ & $1 / 1(100.0)$ & $1 / 1(100.0)$ \\
\hline South Dakota & $0 / 0(0.0)$ & $2 / 2(100.0)$ & $2 / 2(100.0)$ \\
\hline Tennessee & $1 / 1(100.0)$ & $5 / 6(83.3)$ & $6 / 7(85.7)$ \\
\hline Virginia & $0 / 0(0.0)$ & $0 / 1(0.0)$ & $0 / 1(0.0)$ \\
\hline Wisconsin & $0 / 0(0.0)$ & $0 / 1(0.0)$ & $0 / 1(0.0)$ \\
\hline Total & $16 / 55(29.1)$ & $61 / 126(48.4)$ & $77 / 181(42.5)$ \\
\hline
\end{tabular}

\section{Results}

\subsection{Prevalence of PBoV in China and America}

We collected 403 pig samples from five Chinese provinces and 181 samples from 18 American states and identified the positive samples with PBoV NS1-specific PCR primers. The PCR detection results for all of the samples showed that the positive rates of $\mathrm{PBoV}$ $(42.0 \%, 76 / 181)$ in the American samples were significantly higher than those $(11.4 \%, 46 / 403)$ in the Chinese samples $\left(p<0.01, X^{2}\right.$ test; Tables 1 and 2). In the Chinese samples, the prevalences of PBoV in the inguinal lymph node $(27.2 \%, 28 / 103)$ and the spleen $(20.8 \%$, $11 / 53$ ) were significantly higher than those in the submandibular lymph node $(6.3 \%, 5 / 80)$ and tonsil $(1.3 \%, 2 / 130)$ (Table 1$)$. In the American samples, the virus was detected at a higher rate in intestinal samples $(48.6 \%, 72 / 148)$ than in lung samples $(29.1 \%, 16 / 55)$ (Table 2).

\subsection{PBoV3 subtypes, including PBoV3C (group 3), PBoV5 (group 4), and PBoV3/4 (group 5), are epidemic in China and America}

To better understand the genetic relationship of Chinese or American PBoV strains, we purified 20 PCR products from five provinces of China and 37 PCR products from 18 states of the USA, and the products were sequenced three times. These new NS1 sequences and 77 high-quality sequences from GenBank were aligned and phylogenetically analyzed with the NJ and ML methods by MEGA5.2. The NJ and ML trees have an identical topology structure. A phylogenetic tree based on the NS1 gene from China takes shape in two major clades: the PBoV1/2 clade and the PBoV3 clade. The PBoV1/2 clade contains the PBoV1 (group 1) and PBoV2 (group 2) clusters, whereas the PBoV3 clade contains the PBoV3C (group 3), PBoV5 (group 4), and PBoV3/4 (group 5) clusters (Fig. $1 \mathrm{~A}$ and Fig. S1A). The phylogenetic tree of the NS1 gene from America only includes three clusters of PBoV3C (group 3), PBoV5 (group 4), and PBoV3/4 (group 5) (Fig. 1B and Fig. S1B), as further demonstrated by a phylogenetic analysis with all NS1 sequences from China and America (Fig. 1C and Fig. S1C). All new NS1 sequences from China and the USA are located in the PBoV3 clade (Fig. 1 and Fig. S1), which indicates that the PBoV3 subtypes, including PBoV3C (group 3), PBoV5 (group 4), and PBoV3/4 (group 5), are epidemic in China and America. 

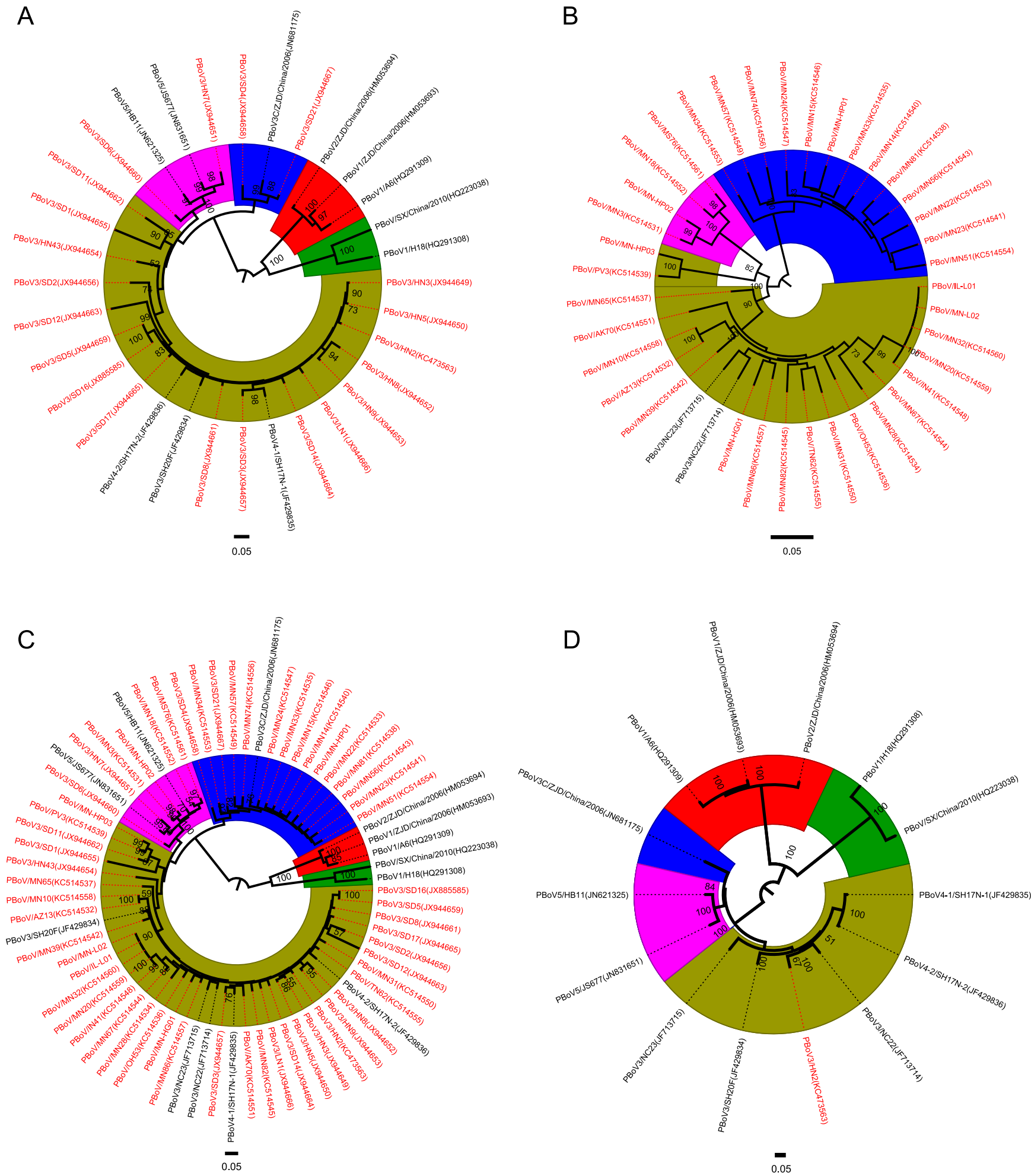

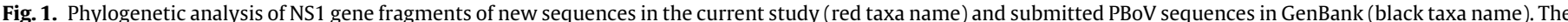

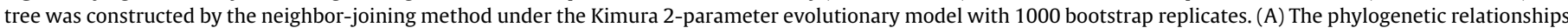

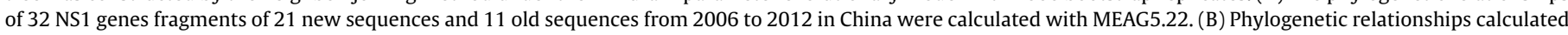

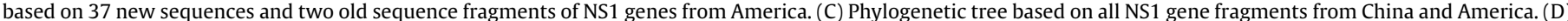

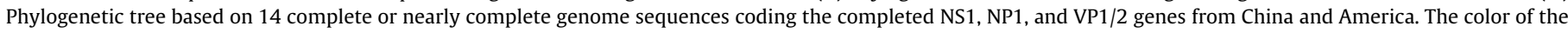

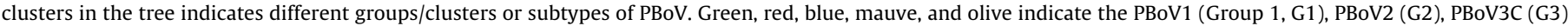

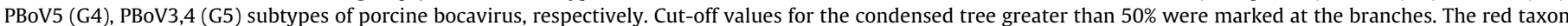

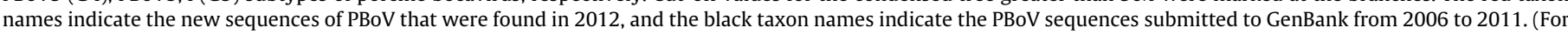
interpretation of the references to color in this figure legend, the reader is referred to the web version of this article.) 
Table 3

Average evolutionary divergence over sequence pairs within and between groups of PBoV in China (NS1 gene).

\begin{tabular}{|c|c|c|c|c|c|}
\hline \multirow[t]{2}{*}{ New classifying subtypes } & \multirow{2}{*}{$\begin{array}{l}\text { Distances within } \\
\text { groups (means } \pm \mathrm{SE} \text { ) }\end{array}$} & \multicolumn{4}{|c|}{ Distances between groups (means $\pm \mathrm{SE}$ ) } \\
\hline & & PBoV1 (G1) & PBoV2 (G2) & PBoV3C (G3) & PBoV5 (G4) \\
\hline PBoV1 (G1) & $0.254 \pm 0.022$ & & & & \\
\hline PBoV2 (G2) & $0.061 \pm 0.008$ & $0.580 \pm 0.038$ & & & \\
\hline PBoV3C (G3) & $0.086 \pm 0.011$ & $0.706 \pm 0.045$ & $0.532 \pm 0.034$ & & \\
\hline PBoV5 (G4) & $0.090 \pm 0.009$ & $0.683 \pm 0.044$ & $0.570 \pm 0.037$ & $0.214 \pm 0.016$ & \\
\hline PBoV3,4 (G5) & $0.119 \pm 0.007$ & $0.718 \pm 0.046$ & $0.615 \pm 0.038$ & $0.227 \pm 0.015$ & $0.203 \pm 0.014$ \\
\hline
\end{tabular}

Table 4

Average evolutionary divergence over sequence pairs within and between groups of PBoV in the USA (NS1 gene).

\begin{tabular}{|c|c|c|c|}
\hline \multirow[t]{2}{*}{ New classifying subtypes } & \multirow[t]{2}{*}{ Distances within groups (means $\pm \mathrm{SE}$ ) } & \multicolumn{2}{|c|}{ Distances between groups (means $\pm \mathrm{SE}$ ) } \\
\hline & & PBoV3C (G3) & PBoV5 (G4) \\
\hline PBoV3C (G3) & $0.071 \pm 0.008$ & & \\
\hline PBoV5 (G4) & $0.059 \pm 0.008$ & $0.249 \pm 0.022$ & \\
\hline PBoV3,4 (G5) & $0.086 \pm 0.009$ & $0.240 \pm 0.021$ & $0.211 \pm 0.019$ \\
\hline
\end{tabular}

\subsection{The PBoV1 and PBoV2 subtypes are unique to China, whereas} the PBoV3 subtypes co-exist in China and America

To correctly classify our new sequences of PBoV, we calculated the nucleotide distances between and within groups identified in the phylogenetic analysis to indicate the subtype demarcations. The average distances between the groups are more than twice or nearly twice the average distance within the groups (Tables 3-5), which demonstrates the veracity of the phylogenetic trees. Furthermore, we constructed a phylogenetic tree with 14 complete or nearly complete genome sequences from China and the USA because the genome sequence included all $\mathrm{PBoV}$ information. The genome tree with PBoV1 (group 1), PBoV2 (group 2), PBoV3C (group 3), PBoV5 (group 4), and PBoV3/4 (group 5) clusters had a topology structure that was similar to that of the NS1 gene tree (Fig. 1D and Fig. S1D). These evolutionary distances of the genome sequences are also similar to those of the NS1 gene sequences (Table 6). The evidence provided by the evolutionary distance and topology structure of the genome and the NS1 gene trees further confirms that these PBoV1 (group 1), PBoV2 (group 2), PBoV3C (group 3), PBoV5 (group 4), and PBoV3/4 (group 5) subtypes are valid new subtype classifications.

To further verify the results of the phylogenetic tree and the evolutionary distances, the sequences were further used for mutation network analysis with NETWORK4.611. The Chinese sequences formed five independent subtypes (groups) (Fig. 2A), and the American sequences formed tree independent subtypes (groups)
(Fig. 2B). Notably, these results coincide with the phylogenetic analyses (Fig. 1 and Fig. S1), indicating that PBoV1 and PBoV2 are distinctive subtypes in China, whereas the PBoV3 subtypes co-exist in China and America (Figs. 1 and 2 and Fig. S1). In addition, we deduced five and three ancestor sequences of the PBoV subtypes (groups) in China and America, respectively. Phylogenetic trees based on the ancestor sequences have a topology structure similar to that of the phylogenetic trees based on the original NS1 gene and the genome sequences of PBoV (Fig. 3), indicating that each subtype (group) originated from different sequences. Furthermore, the 75 NS1 sequences and 18 genome sequences were aligned and constructed evolutionary tree to investigate the phylogenetic relationship between PBoV and HBoV. The results show that the evolutionary relationship of PBoV1 (group 1) and HBoV14 is nearer than that of PBoV1 (group 1) and other PBoV (groups 2-5) (Fig. S2), which indicate it could be a further source of human infection.

\subsection{Classification and distribution of PBoV subtypes in China and the USA}

Due to the deficiency of PBoV sequences in the past, some viruses may be divided into incorrect subtypes or may not fit into the current subtype classification. Many sequences of PBoV that were recently submitted to GenBank have remained unclassified. Thus, we constructed a phylogenetic tree and then drew contrast maps of the locations of the new and originally

Table 5

Average evolutionary divergence over sequence pairs within and between groups of PBoV in China and the USA (NS1 gene).

\begin{tabular}{|c|c|c|c|c|c|}
\hline \multirow[t]{2}{*}{ New classifying subtypes } & \multirow{2}{*}{ Distances within groups (means $\pm \mathrm{SE}$ ) } & \multicolumn{4}{|c|}{ Distances between groups (means $\pm \mathrm{SE}$ ) } \\
\hline & & PBoV1 (G1) & PBoV2 (G2) & PBoV3C (G3) & PBoV5 (G4) \\
\hline PBoV1 (G1) & $0.255 \pm 0.025$ & & & & \\
\hline PBoV2 (G2) & $0.065 \pm 0.009$ & $0.613 \pm 0.046$ & & & \\
\hline PBoV3C (G3) & $0.076 \pm 0.007$ & $0.752 \pm 0.057$ & $0.544 \pm 0.040$ & & \\
\hline PBoV5 (G4) & $0.080 \pm 0.008$ & $0.704 \pm 0.051$ & $0.571 \pm 0.043$ & $0.240 \pm 0.019$ & \\
\hline PBoV3,4 (G5) & $0.124 \pm 0.010$ & $0.751 \pm 0.055$ & $0.662 \pm 0.048$ & $0.246 \pm 0.020$ & $0.213 \pm 0.010$ \\
\hline
\end{tabular}

Table 6

Average evolutionary divergence over sequence pairs within and between groups of PBoV in China and America (genome).

\begin{tabular}{|c|c|c|c|c|c|}
\hline \multirow[t]{2}{*}{ New classifying subtypes } & \multirow[t]{2}{*}{ Distances within groups (means $\pm \mathrm{SE}$ ) } & \multicolumn{4}{|c|}{ Distances between groups (means $\pm \mathrm{SE}$ ) } \\
\hline & & PBoV1 (G1) & PBoV2 (G2) & PBoV3C (G3) & PBoV5 (G4) \\
\hline PBoV1 (G1) & $0.116 \pm 0.005$ & & & & \\
\hline PBoV2 (G2) & $0.063 \pm 0.003$ & $0.877 \pm 0.020$ & & & \\
\hline PBoV3C (G3) & $\mathrm{n} / \mathrm{c}$ & $0.883 \pm 0.021$ & $0.737 \pm 0.017$ & & \\
\hline PBoV5 (G4) & $0.087 \pm 0.004$ & $0.822 \pm 0.020$ & $0.748 \pm 0.019$ & $0.212 \pm 0.007$ & \\
\hline PBoV3,4 (G5) & $0.126 \pm 0.003$ & $0.842 \pm 0.018$ & $0.755 \pm 0.017$ & $0.238 \pm 0.007$ & $0.207 \pm 0.006$ \\
\hline
\end{tabular}




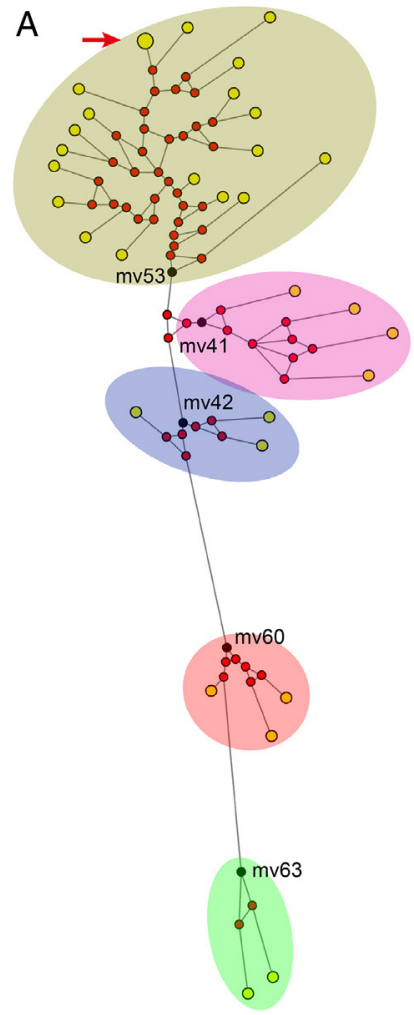

B

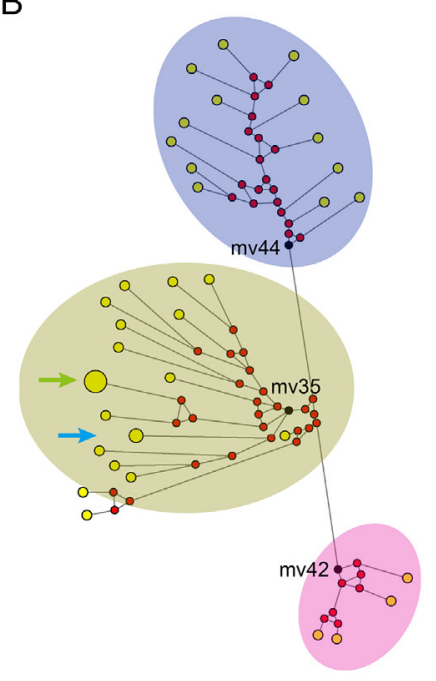

C

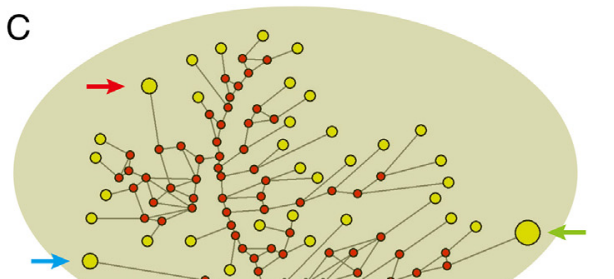

(1)

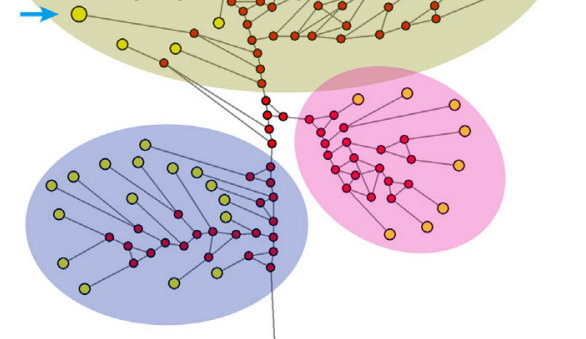

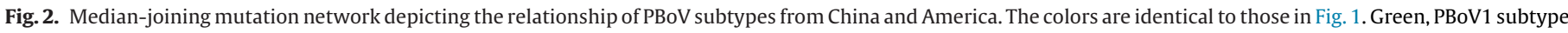

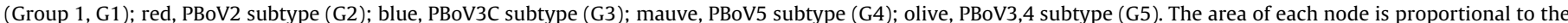

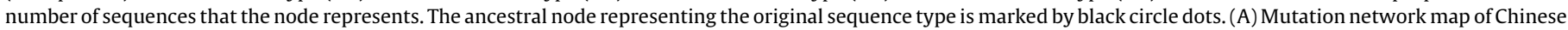

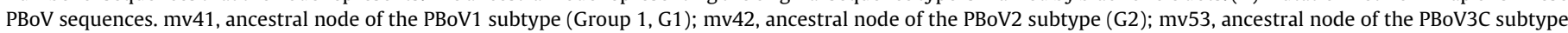

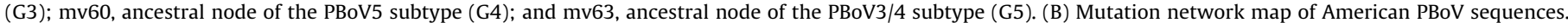

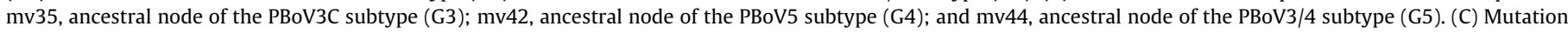

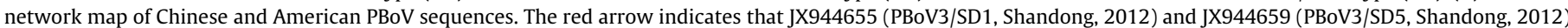

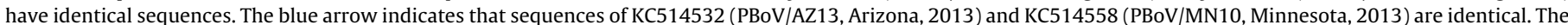

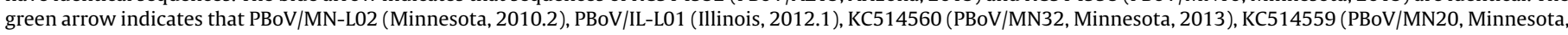

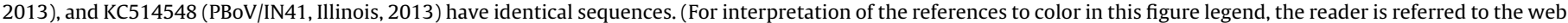
version of this article.)

defined subtypes of PBoV in ArcGIS (Fig. 4). The phylogenetic tree, which was constructed with 19 NS1 gene sequences of non-subtyping PBoV, suggested that the NS1 genes with approximately 200 bp from Hebei Province in 2006 belong to the PBoV2 subtype (Fig. S3A). Three non-subtyping sequences of the NP1 gene, namely HQ910446 (Fujian, 2010), HQ910447 (Hubei, 2010), and HQ872052 (Jiangsu, 2011), were calculated to generate an evolutionary tree, which indicated that they were all grouped into the PBoV1 subtype (Fig. S3B). Another phylogenetic tree, which was constructed with 19 VP1 gene sequences of nonsubtyping PBoV, showed that these PBoVs from Anhui, Beijing, Henan, Hebei, Jiangsu, Jiangxi, Shanghai, Xinjiang, and Zhejiang Provinces in 2009 correspond to the PBoV1 subtype (Fig. S3C). Furthermore, to find a fit subtype classification for old sequences of $\mathrm{PBoV}$, the phylogenetic tree of the NS1 gene with approximately 300 bp suggested that PBoV1-HQ910442 (Henan, 2010) and PBoV1HQ910443 (Shandong, 2010) are similar to PBoV1/A6-HQ291309, that PBoV2-HQ910445 (Shanghai, 2010) and PBoV2-HQ910444 (Jiangsu, 2010) are similar to PBoV1/ZJD/China/2006-HM053693, and that all of these strains, along with PBoV2/ZJD/China/2006HM053694 from Hebei Province, belong to the PBoV2 subtype (Fig. S3D). In addition, we analyzed the distinctive group of PBoV6V and PBoV7V by constructing a phylogenetic tree from 54 VP1 gene sequences with approximately $400 \mathrm{bp}$. The results indicated that PBoV6V and PBoV7V form a distinctive cluster compared with the other five clusters (PBoV1 (group 1), PBoV2 (group 2), PBoV3C (group 3), PBoV5 (group 4), and PBoV3/4 (group 5) clusters) and were defined as the PBoV6V7V subtype (group 6) of porcine bocavirus belonging to the PBoV3 clade (Fig. S3E). PBoV7VHQ910440 (Hubei, 2010) and PBoV7V-HQ910441 (Zhejiang, 2010) were clustered in the PBoV6V7V subtype (group 6), whereas the other four PBoV6V sequences, HQ910436, HQ910437, and HQ910438 from Fujian, and HQ910439 from Shanghai in 2010, were grouped into the PBoV3 cluster (Fig. S3E).

The unique PBoV3 subtype was found in America in 2010 (Fig. 4B). All of the originally defined subtypes of PBoV, comprising PBoV1, PBoV2, PBoV3, PBoV4, PBoV5, PBoV3C, PBoV6V, and PBoV7V, have been found in China from 2006 to 2012 (Fig. 4A). PBoV1 and PBoV2 are more dispersed across the provinces and have been recorded there for a longer time, from 2006 to 2011, compared with other subtypes of PBoV (Fig. 4A). PBoV3 and PBoV4 were only identified from Hong Kong in 2007, and PBoV3C was isolated from Hebei in 2006, whereas PBoV5 was discovered from Jiangsu and Hubei in 2011 (Fig. 4A). The PBoV3 subtypes, including the PBoV3C subtype (G3), the PBoV5 subtype (G4), and the PBoV3/4 subtype (G5), were found in China and the USA in 2012 (Fig. 4). In summary, the aforementioned results indicate that PBoV1 and PBoV2 were epidemic strains from 2006 to 2011 in China, whereas the PBoV3 subtypes were epidemic strains from 2010 to 2012 in both China and the USA. 
A

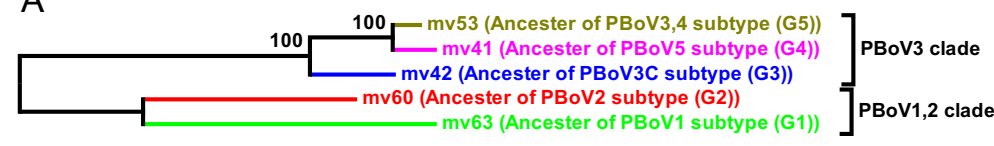

0.05

B

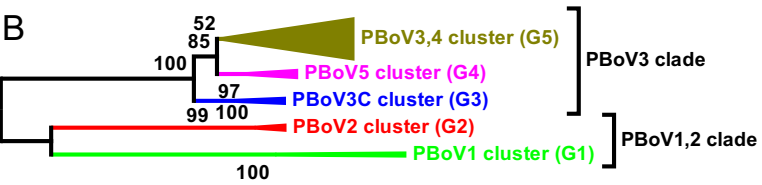

$\overrightarrow{0.05}$
D

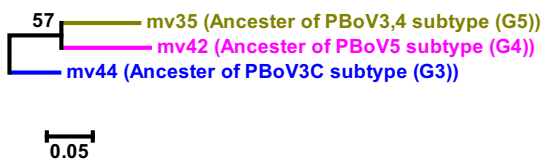

$\mathrm{E}$

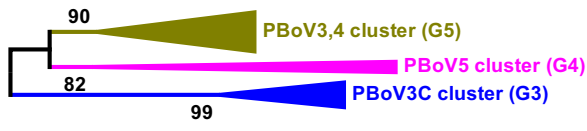

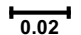

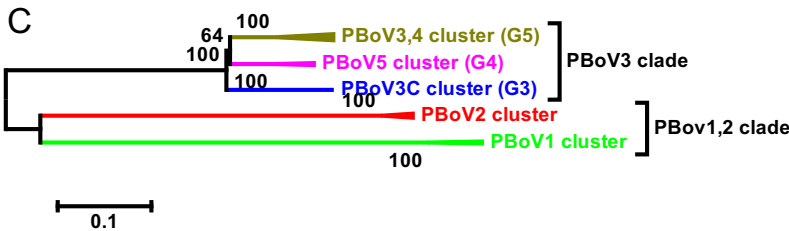

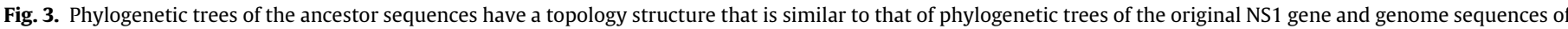

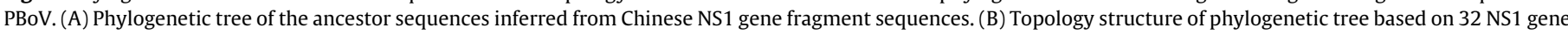

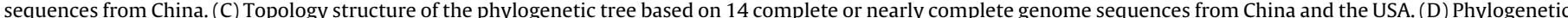

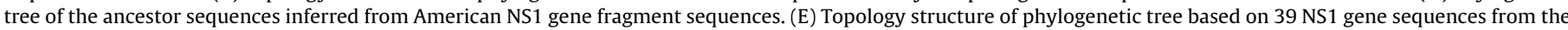

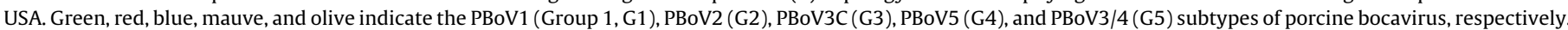
(For interpretation of the references to color in this figure legend, the reader is referred to the web version of this article.)

\subsection{The geographical distribution of PBoV mainly lies in the east and south coastal areas of China and the American central states}

To investigate the geographical distribution of PBoV, we statistically treated the spatial and temporal information of PBoV sequences from GenBank (July, 2013), the new emerging PBoV cases, and records in published scholarly papers regarding China and America. After filtering the records without an exact location and date, the distribution map was drawn using the ArcGIS geographic information system software based on 591 old cases and 46 new emerging cases in China and eight old cases and 77 new emerging cases in the USA. The geographical distribution map suggested that PBoV mainly lies in the east and south coastal areas of China and the central states of the USA (Fig. 5). The old PBoV case involved 14 provinces and regions in China, including Jiangsu, Shanghai, Anhui, Shandong, Hebei, Zhejiang, Fujian, Beijing, Henan, Hubei, Jiangxi, Guizhou, Xinjiang, and Hong Kong (Fig. 5A), and the state of North Carolina in the USA (Fig. 5B). In contrast, the new emerging cases involved five provinces in China, including Shandong, Hebei, Henan, Liaoning, Tianjin, and 13 states in the USA, including North Carolina, Minnesota, Arizona, Oklahoma, Pennsylvania, Illinois, Arkansas, Tennessee, Missouri, Colorado, Iowa, Nebraska, and South Dakota (Fig. 5B). Liaoning Province and Tianjin City in China and the American states of Minnesota, Arizona, Oklahoma, Pennsylvania, Illinois, Arkansas, Tennessee, Missouri, Colorado, Iowa, Nebraska, and South Dakota first reported that piglets were infected with PBoV (Fig. 5).

\subsection{The center of high occurrence frequency of PBoV was located in Jiangsu Province and the state of Minnesota and radiated to other places in China and America}

We also statistically count the outbreak frequency based on information from 722 cases and 161 sequences from China and America and treated them using ArcGIS9.2. There are at least three outbreaks of $\mathrm{PBoV}$ in seven provinces of China, including Jiangsu, Shanghai, Shandong, Zhejiang, Hubei, and Henan (Fig. 5A).
The center of high outbreak frequency of PBoV located in Jiangsu Province achieves six outbreaks (Fig. 5A). The frequency of outbreaks in Shandong, Anhui, and Zhejiang Provinces and Shanghai City surrounding the center was at least four (Fig. 5A). In contrast, at least three outbreaks of PBoV occurred in three states, namely Minnesota, Illinois, and Arkansas, in America (Fig. 5B). The center of high outbreak frequency of $\mathrm{PBoV}$ in the state of Minnesota exhibited six outbreaks (Fig. 5B).

\subsection{Hong Kong, Hebei, and Jiangsu Provinces and the states of Minnesota and North Carolina were possibly the geographic origins of PBoV in China and America, respectively}

To analyze the geographical origin and transmission possibility of PBoV in China and America, respectively, the ancestral locations of PBoV were estimated based on the maximum parsimony criterion. According to these results, we constructed the transmission possibility maps of PBoV for China and America (Fig. 6). The phylogeographical inference shown in Fig. 6A and Fig. S4A indicated that PBoV1/A6 (HQ291309) of PBoV2 subtype (group 2) in Jiangsu, Shanghai, Shandong, Anhui, or Guizhou originated from Hebei, whereas PBoV/SX/China/2010 (HQ223038) of the PBoV1 subtype (group 1) in Hubei originated from Jiangsu, Shanghai, Shandong, Anhui, or Guizhou. Another maximum parsimony tree indicated that the PBoV2 subtype (group 2), including HQ910445 (Shanghai, 2010), HQ910444 (Jiangsu, 2010), HQ910442 (Henan, 2010), and HQ910443 (Shandong, 2010) originated from Hebei (Fig. 6A and Fig. S4B). PBoV3C/ZJD/China/2006 (JN681175) of the PBoV3C subtype (group 3) may have dispersed from Hebei to Shandong Province (Fig. 6A and Fig. S4C). The phylogeographical analysis of the PBoV5 subtree (group 4) indicated that PBoV5/JS677 (JN831651) was possibly transmitted from Jiangsu to Shandong, Henan, and Hubei Provinces (Fig. 6A and Fig. S4D). In contrast, some strains of the PBoV3,4 subtree (group 5) in Shandong originated from Hong Kong (Fig. 6A and Fig. S4E). The PBoV6V7V subtype (group 6), including HM053672 and HM053673 (Hebei, 2006), may have dispersed from Hebei to Hubei (HQ910440, 2010) and Zhejiang (HQ910441, 2010) 

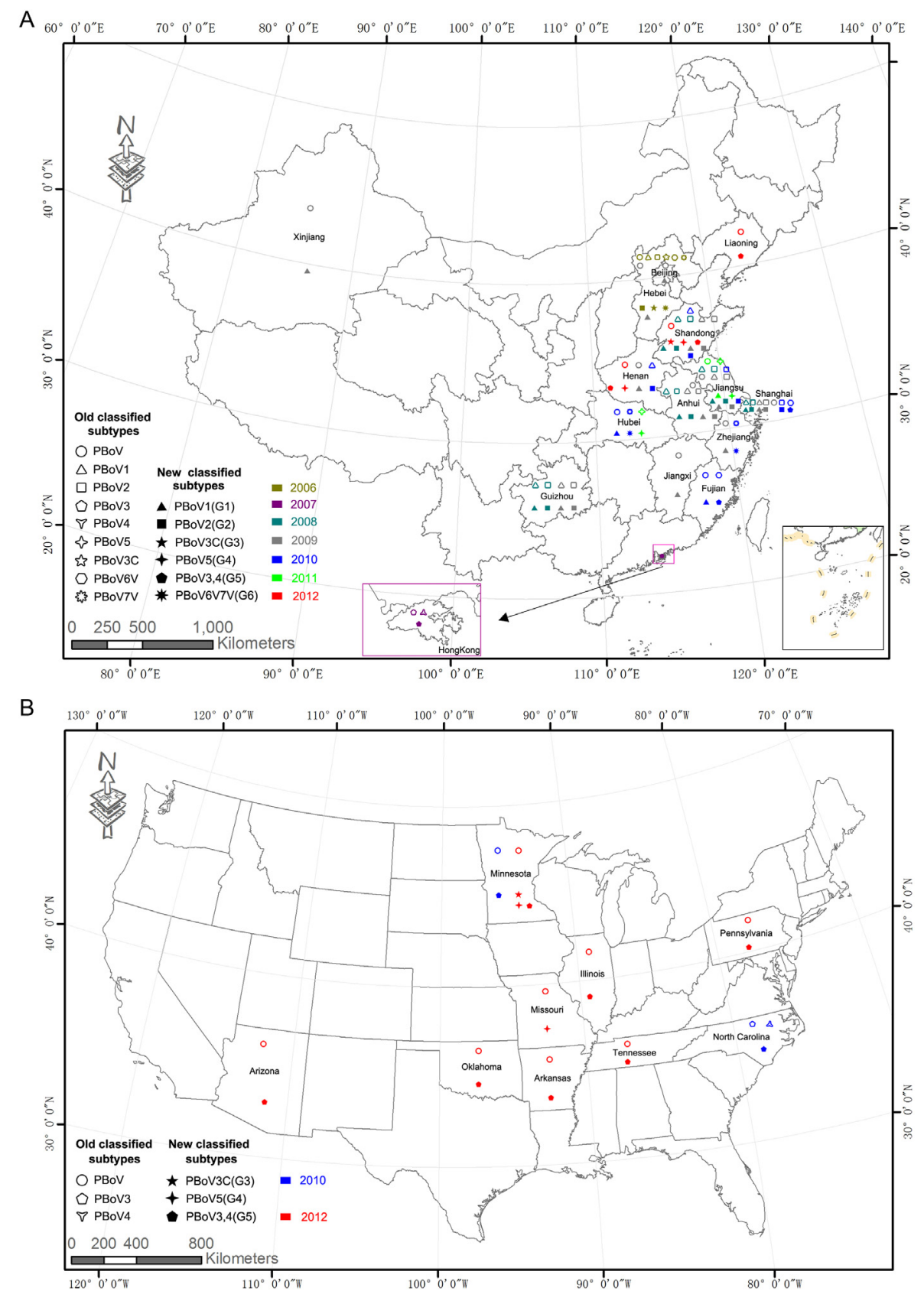

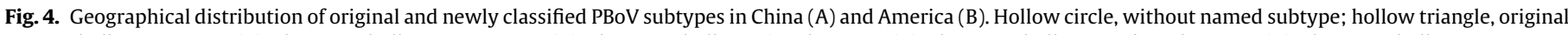

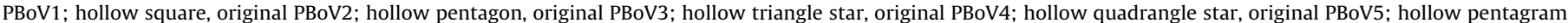

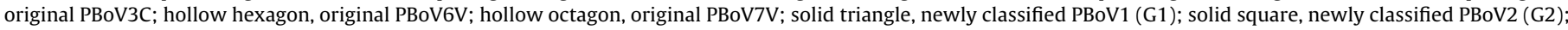

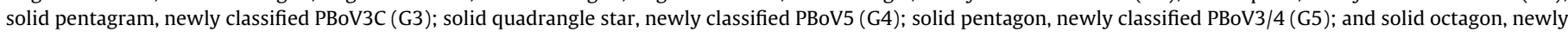

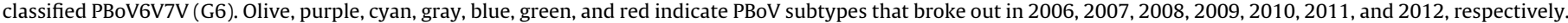
(For interpretation of the references to color in this figure legend, the reader is referred to the web version of this article.)

Provinces (Fig. 6A and Fig. S4F). In America, the phylogeographical analysis indicated that PBoV/MN-HP03 of the PBoV5 subtree (group 4) may have been transmitted in Minnesota or from Minnesota to Missouri (Fig. 6B and Fig. S4G). The PBoV3C subtype (group 3) only existed and was dispersed in Minnesota (Fig. 6B and Fig. S4H), whereas the PBoV3,4 subtree (group 5) may have been transmitted from North Carolina to Minnesota and from Minnesota to Illinois, Tennessee, and Arizona (Fig. 6B and Fig. S4I). These results suggested that Hong Kong, Hebei, and Jiangsu Provinces are likely the geographical origin of PBoV in China. In contrast, the states of Minnesota and North Carolina were likely the geographical origin of $\mathrm{PBoV}$ in America.

\section{Discussion}

Currently, the pathogenesis of PBoV remains to be clarified. Individual infection of PBoV usually causes no apparent clinical signs, and the co-infection of PBoV could make the clinical signs more obvious (Kesebir et al., 2006). Many scientists have also reported that PBoV exhibit varying prevalence rates with a wide range from $1.5 \%$ to $88 \%$ in pig samples from different regions (Blomstrom et al., 2009, 2010; Zhai et al., 2010; Cadar et al., 2011; Li et al., 2011; McKillen et al., 2011; Shan et al., 2011a; Zeng et al., 2011; Zhang et al., 2011). In the present manuscript, compared with other organs in Chinese samples, the spleen (20.8\%) and inguinal lymph node 


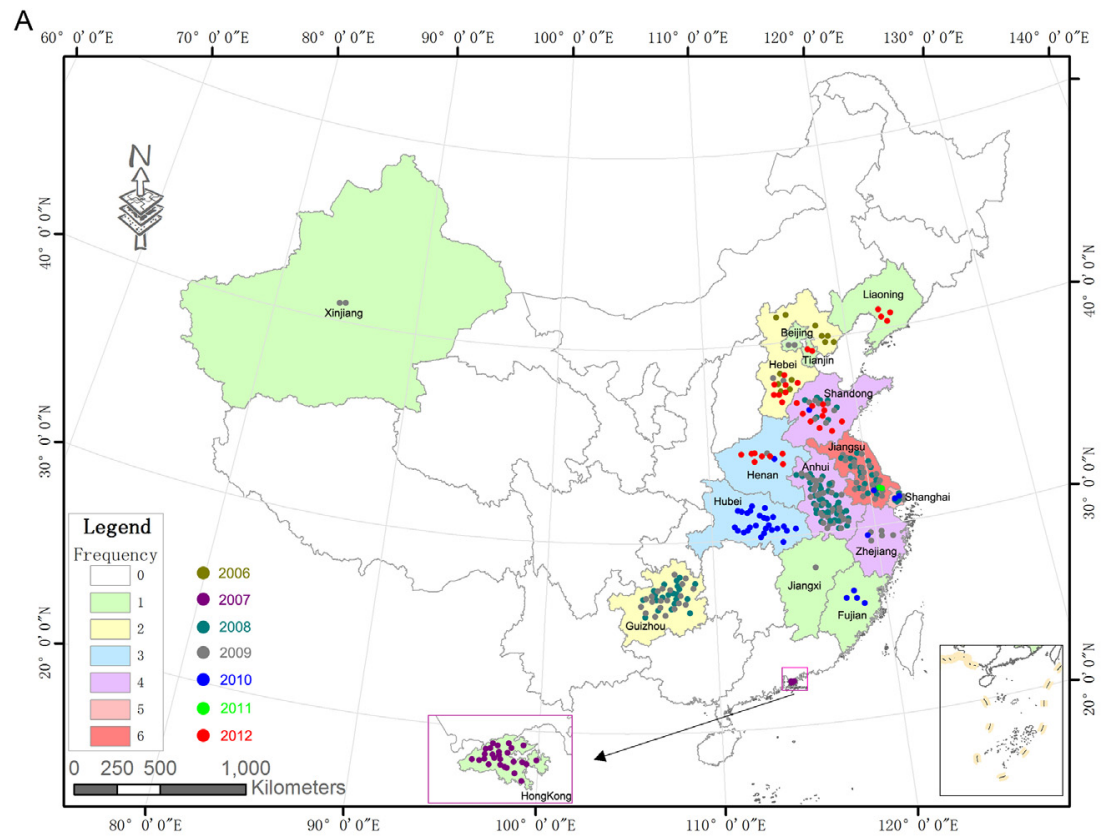

B

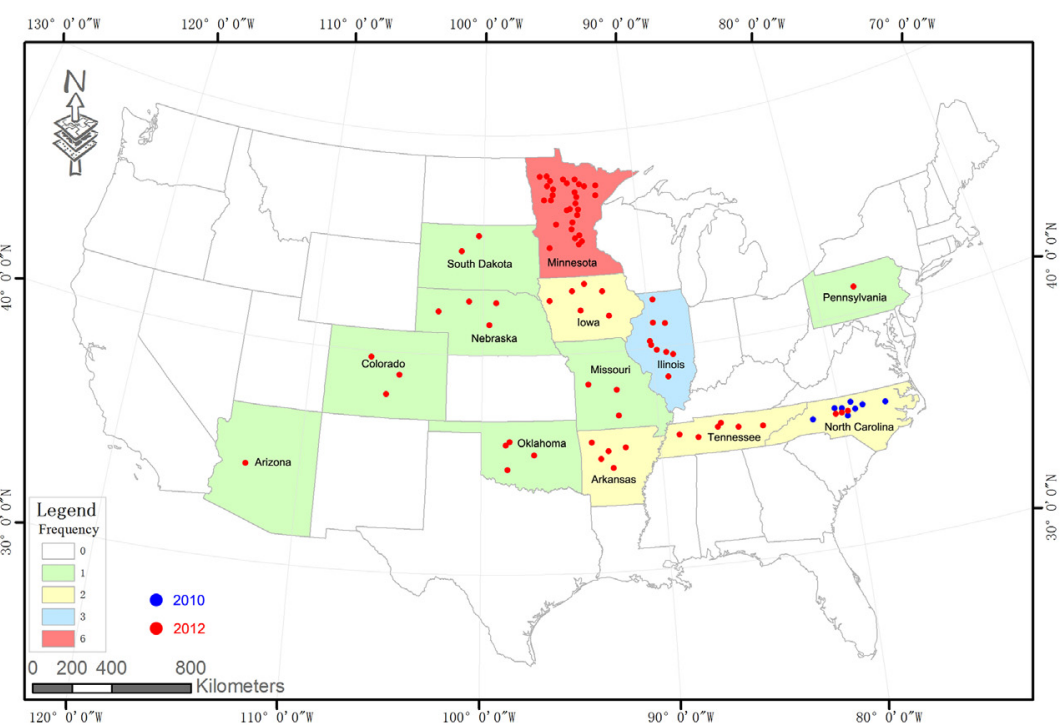

Fig. 5. Geographical distribution and outbreak frequency of porcine bocavirus in China (A) and the USA (B).

(27.2\%) have much higher positive rates, suggesting that they are organs in which PBoV replication likely easily takes place. In addition, only 1 in 130 tonsil samples $(0.77 \%)$ collected from 50 - to 70-day-old pigs in farms performing the classic swine fever virus (CSFV) eradication program in Tianjin region were detected as positive. The rate is significantly lower $(p<0.05)$ compared with that obtained with farms that are not performing the eradication program (5\%). The difference between the different groups implies that the CSFV eradication plan may be of help to decrease the coinfection of PBoV. Other scientists have also found that PBoV has markedly higher infection rates in diseased pigs than in healthy pigs and is often co-infected in post-weaning piglets with PCV2, PRRSV and PTTV2 (Zhai et al., 2010). In contrast, in American samples, we found $29.1 \%$ and $48.4 \%$ cases (respiratory and gastrointestinal, respectively) that were positive for PBoV with an overall positivity of $42.5 \%$. These findings are similar to those reported by Lau et al., who reported $70 \%$ positivity for PBoV3 and PBoV4 in Hong Kong (Lau et al., 2011).
Despite the wealth of sequence data in the databases, there has been no satisfactory classification system to cover the diversity of all available $\mathrm{PBoV}$ sequences. We grouped the $\mathrm{PBoV}$ from China and USA into five subtypes, including PBoV1 (G1), PBoV2 (G2), PBoV3C (G3), PBoV5 (G4), and PBoV3/4 (G5) based on the results of the phylogenetic analysis, evolutionary distances, and mutation network with NS1 gene sequences. The classifying subtypes of PBoV with 14 complete or nearly complete genome sequences from China and the USA were consistent with those of NS1 gene sequences and further proved the veracity of classifying subtypes of PBoV. The third piece of evidence came from a mutation network analysis of NS1 gene sequences, which can infer the ancestor sequences of five PBoV subtypes (groups). The topology structure of the ancestor sequences of five PBoV subtypes was also consistent with that of the NS1 gene or genome sequences, which include the PBoV1, 2 clade and the PBoV3 clade. The PBoV1, 2 clade, which consists of the PBoV1 (G1) cluster (HQ291308 and HQ223038) and the PBoV2 (G2) cluster (HQ291309, HM053693, and HM053694), is similar with 


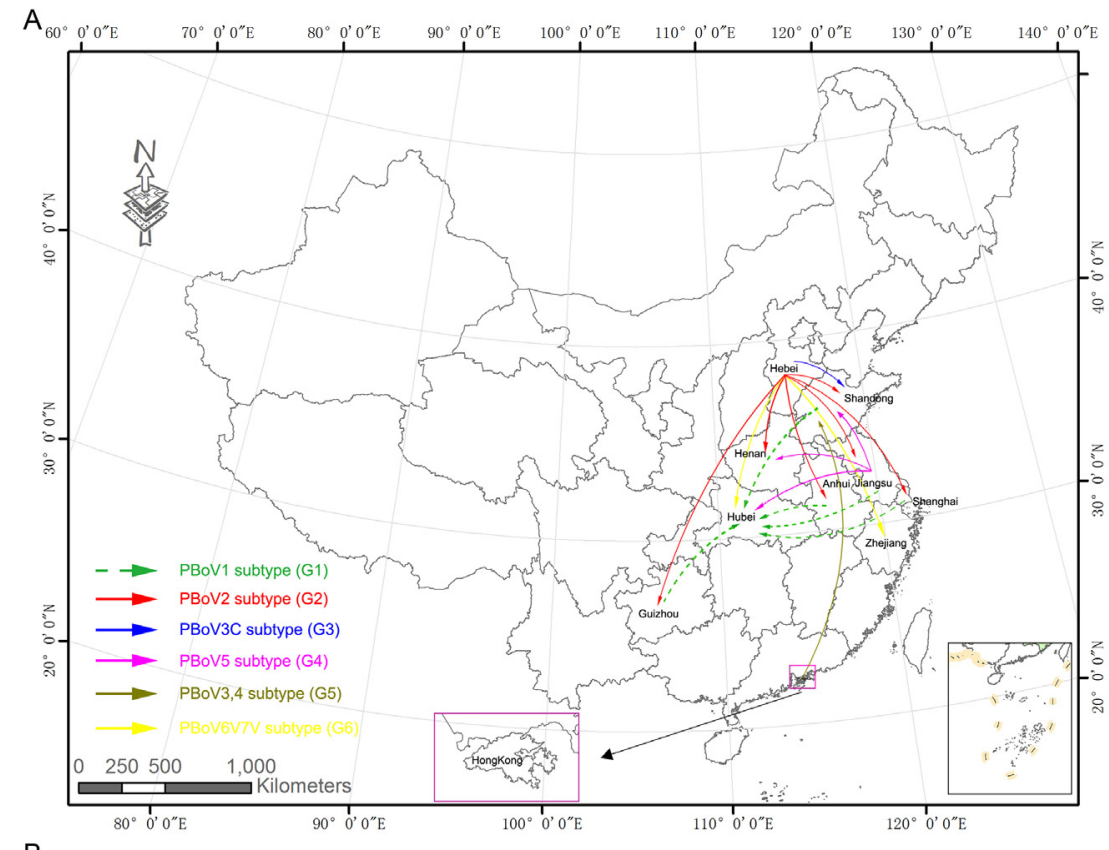

B

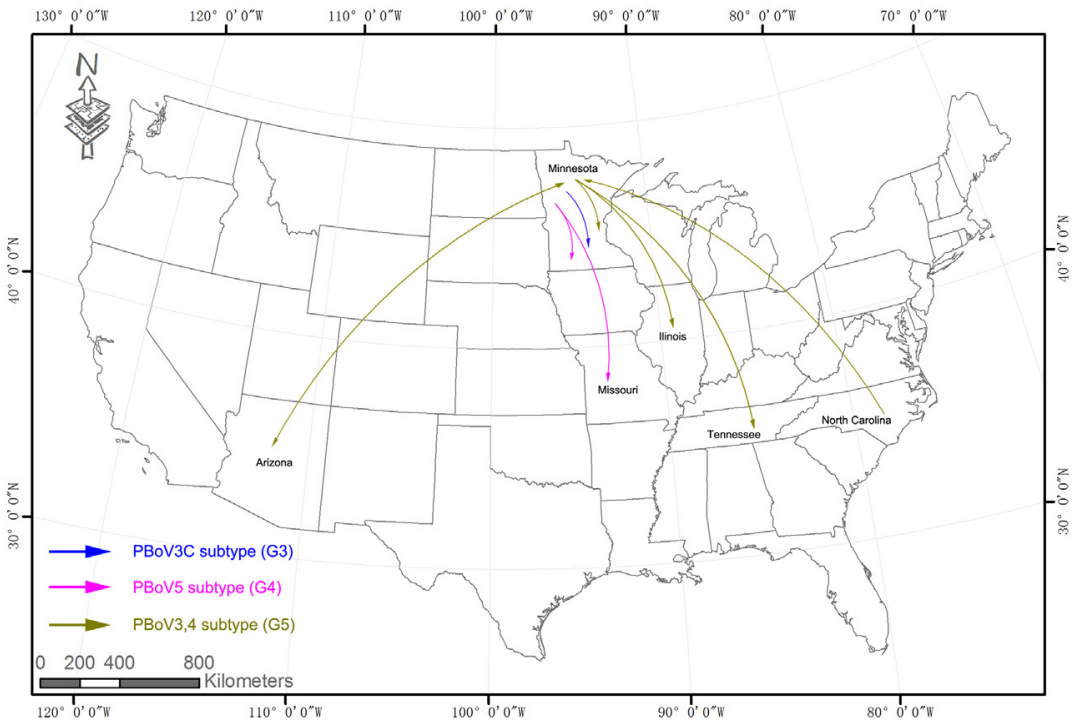

Fig. 6. Transmission possibility of PBoV as inferred by the maximum parsimony criterion based on gene sequences of PBoV isolated from China (A) and the USA (B) from 2006 to 2012.

that obtained from a phylogenetic analysis performed in a previous study (Shan et al., 2011a; Yang et al., 2012; Xiao et al., 2013). Interestingly, PBoV1 cluster has a nearer phylogenetic relationship with HBoV1-4 than that with PBoV2 cluster or PBoV3 clade, which indicate it could be a further source of human infection by pigs or meat from pigs. In the present study, the PBoV3 clade can be grouped into PBoV3C (G3), PBoV5 (G4), and PBoV3/4 (G5) clusters based on the results of the phylogenetic analysis, evolutionary distance, and mutation network, whereas Xiao classified the PBoV3 clade into five subgroups, including PBoV3A-E (Xiao et al., 2013) using the species demarcation criteria delineated by the International Committee on Taxonomy of Viruses (ICTV) (species are defined as $<95 \%$ related by NS1 DNA sequences) (Tijssen et al., 2011). The PBoV3C (G3) and PBoV5 (G4) clusters can be supported by a bootstrap value $>80 \%$ and are significantly different between and within groups. In contrast, PBoV3 and PBoV4 were grouped into the PBoV3,4 (G5) cluster because these cannot be supported with a bootstrap value $<60 \%$ and are not significantly different between and within groups, regardless of the NS1, NP1, VP1, and genome sequences.
Due to PBoV-6V and 7V (Cheng et al., 2010) without NS1 sequences, a phylogenetic analysis based on 54 VP1 sequences with approximately 400 bp showed that PBoV-6V and $7 \mathrm{~V}$ are located in the PBoV3 clade and form a separate cluster (PBoV6V7V subtype (G6)) compared with other clusters of the PBoV3 clade, which is similar with the results of Cheng's analysis (Cheng et al., 2010). The topology structure of the phylogenetic tree with 54 VP1 sequences is also similar with that of the NS1 gene and genome sequences, which indicated that the PBoV6V7V subtype (G6) is dependent on the classification with the PBoV VP1 gene sequences.

In the past few years, the PBoV1, PBoV2, PBoV3, PBoV4, PBoV5, PBoV3C, PBoV-6V, and PBoV-7V genotypes were discovered in China (Cheng et al., 2010; Lau et al., 2011; Shan et al., 2011a; Li et al., 2012a; Jiang et al., 2013). PBoV3 and PBoV4 were discovered in the state of North Carolina in the USA in 2010 (Shan et al., 2011b). These genotypes were grouped into the PBoV1 (G1), PBoV2 (G2), PBoV3C (G3), PBoV5 (G4), PBoV3,4 (G5), and PBoV-6V7V (G6) subtypes in the present study. The results of the phylogenetic analysis, evolutionary distances, and mutation network suggested that 
20 and 37 sequences of newly isolated $\mathrm{PBoV}$ cases are clustered in the PBoV3 clade, including PBoV3C (G3), PBoV5 (G4), and PBoV3,4 (G5). The PBoV3C (G3) and PBoV5 (G4) genotypes are new emerging PBoVs in the states of Minnesota and Missouri in the USA. The phylogenetic tree analyzed 19 (by Cheng) and four (by Zhang) partial NS1 gene nucleotide sequences without a named subtype (Cheng et al., 2010) and suggested that these PBoVs belong to the PBoV2 subtype. Another phylogenetic tree analyzed 19 VP1 and three NP1 gene sequences without a named subtype (Zhai et al., 2010), and the findings indicated that these PBoVs belong to the PBoV1 subtype. Furthermore, these evolutionary trees have a topological structure similar to that of the genome and NS1 gene tree. These results indicate that PBoV1 and PBoV2 are epidemic strains from 2006 to 2011 in China, whereas the PBoV3 subtypes were epidemic strains from 2010 to 2012 in China and the USA.

We performed the first comprehensive analysis of the geographical distribution and occurrence frequency of PBoV in China and the USA. To the best of our knowledge, the old PBoV cases involved 14 provinces and regions in China, including Jiangsu, Shanghai, Anhui, Shandong, Hebei, Zhejiang, Fujian, Beijing, Henan, Hubei, Jiangxi, Guizhou, Xinjiang, and Hong Kong, and the state of North Carolina in the USA until 2011 (Cheng et al., 2010; Zhai et al., 2010; Lau et al., 2011; Shan et al., 2011a,b; Zeng et al., 2011; Zhang et al., 2011; Li et al., 2012a; Yang et al., 2012; Xiao et al., 2013). In 2012, the new and emerging cases involved five provinces in China (Shandong, Hebei, Henan, Liaoning, and Tianjin) and 13 states in the USA (North Carolina, Minnesota, Arizona, Oklahoma, Pennsylvania, Illinois, Arkansas, Tennessee, Missouri, Colorado, Iowa, Nebraska, and South Dakota). The geographical distribution of PBoV mainly lies in the east and south coastal areas of China and the central states of the USA. With six outbreaks, Jiangsu Province and the state of Minnesota were the centers of high PBoV occurrence frequency in China and America, respectively.

The crowded conditions of modern swine production and the frequent movement of pigs because of trade provide a beneficial environment for viral transmission and evolution (Shi et al., 2010). The geographic origin and the possibility of transmission of PBoV in China and America were estimated based on the maximum parsimony criterion. Hong Kong, Hebei, and Jiangsu Provinces were possible geographic origins of $\mathrm{PBoV}$ in China. Some strains of the PBoV3/4 subtree (group 5) in Shandong may have originated from Hong Kong. The PBoV2 subtype (group 2), the PBoV3C subtype (group 3), and the PBoV6V7V subtype (group 6) dispersed from Hebei to other provinces in China. The PBoV5 subtype (group 4) was transmitted from Jiangsu to Shandong, Henan, and Hubei Provinces. In the USA, the states of Minnesota and North Carolina were possible geographic origins of the PBoV PBoV3/4 subtree (group 5) and may have been transmitted from North Carolina to Minnesota, whereas the PBoV3C subtype (group 3), the PBoV5 subtree (group 4 ), and the PBoV3/4 subtree (group 5) may have been transmitted from Minnesota to other states in the USA.

\section{Conflict of interest}

The authors declare that there are no potential conflicts of interest with respect to the research, authorship, and/or publication of this article.

\section{Author contribution}

Conceived and designed the experiments: Jinhai Huang. Performed the experiments: Mengmeng Liu, Jinhai Huang, Sunil K. Mor, Caihong Zhang, and Qiangzhe Zhang. Analyzed the data: Qiangzhe Zhang, Caihong Zhang, Mengxu Gao, and Yinghua Diao.
Contributed reagents/materials/analysis tools: Jinhai Huang and Sagar M. Goyal. Wrote the paper: Qiangzhe Zhang and Jinhai Huang.

\section{Acknowledgements}

The authors thank Dr. Jun Han at Penn State College of Medicine for critically reading the manuscript and providing thoughtful comments. This work was supported by the National Natural Science Foundation of China (No. 31272540) and the Ministry of Education, Science and Technology Development Center (No. 20130031120040).

\section{Appendix A. Supplementary data}

Supplementary data associated with this article can be found, in the online version, at http://dx.doi.org/10.1016/j.virusres.2014. 09.012.

\section{References}

Allander, T., Tammi, M.T., Eriksson, M., Bjerkner, A., Tiveljung-Lindell, A., Andersson, B., 2005. Cloning of a human parvovirus by molecular screening of respiratory tract samples. Proc. Natl. Acad. Sci. U. S. A. 102, 12891-12896.

Bandelt, H.J., Forster, P., Rohl, A., 1999. Median-joining networks for inferring intraspecific phylogenies. Mol. Biol. Evol. 16, 37-48.

Binn, L.N., Lazar, E.C., Eddy, G.A., Kajima, M., 1970. Recovery and characterization of a minute virus of canines. Infect. Immun. 1, 503-508.

Blomstrom, A.L., Belak, S., Fossum, C., Fuxler, L., Wallgren, P., Berg, M., 2010. Studies of porcine circovirus type 2, porcine boca-like virus and torque teno virus indicate the presence of multiple viral infections in postweaning multisystemic wasting syndrome pigs. Virus Res. 152, 59-64.

Blomstrom, A.L., Belak, S., Fossum, C., McKillen, J., Allan, G., Wallgren, P., Berg, M., 2009. Detection of a novel porcine boca-like virus in the background of porcine circovirus type 2 induced postweaning multisystemic wasting syndrome. Virus Res. 146, 125-129.

Blomstrom, A.L., Stahl, K., Okurut, A.R., Masembe, C., Berg, M., 2013. Genetic characterisation of a porcine bocavirus detected in domestic pigs in Uganda. Virus Genes 47, 370-373.

Cadar, D., Csagola, A., Lorincz, M., Tombacz, K., Kiss, T., Spinu, M., Tuboly, T., 2011. Genetic detection and analysis of porcine bocavirus type 1 (PoBoV1) in European wild boar (Sus scrofa). Virus Genes 43, 376-379.

Chen, K.C., Shull, B.C., Moses, E.A., Lederman, M., Stout, E.R., Bates, R.C., 1986. Complete nucleotide sequence and genome organization of bovine parvovirus. J. Virol. 60, 1085-1097.

Cheng, W.X., Li, J.S., Huang, C.P., Yao, D.P., Liu, N., Cui, S.X., Jin, Y., Duan, Z.J., 2010. Identification and nearly full-length genome characterization of novel porcine bocaviruses. PLoS One 5, e13583.

Choi, M.G., Park, S.J., Nguyen, V.G., Chung, H.C., Kim, A.R., Park, B.K., 2013. Molecular detection and genetic analysis of porcine bocavirus in Korean domestic swine herds. Arch. Virol.

Holmes, E.C., 2004. The phylogeography of human viruses. Mol. Ecol. 13, 745-756.

Jiang, Y.H., Xiao, C.T., Yin, S.H., Gerber, P., Halbur, P., Opriessnig, T., 2013. High prevalence and genetic diversity of porcine bocaviruses (PBoV) in US pigs and identification of multiple novel PBoVs. J. Gen. Virol.

Kapoor, A., Mehta, N., Esper, F., Poljsak-Prijatelj, M., Quan, P.L., Qaisar, N., Delwart, E., Lipkin, W.I., 2010. Identification and characterization of a new bocavirus species in gorillas. PLoS One 5, e11948.

Kesebir, D., Vazquez, M., Weibel, C., Shapiro, E.D., Ferguson, D., Landry, M.L., Kahn, J.S. 2006. Human bocavirus infection in young children in the United States: molec ular epidemiological profile and clinical characteristics of a newly emerging respiratory virus. J. Infect. Dis. 194, 1276-1282.

Larkin, M.A., Blackshields, G., Brown, N.P., Chenna, R., McGettigan, P.A., McWilliam, H., Valentin, F., Wallace, I.M., Wilm, A., Lopez, R., Thompson, J.D., Gibson, T.J., Higgins, D.G., 2007. Clustal $W$ and Clustal X version 2.0. Bioinformatics 23, 2947-2948.

Lau, S.K., Woo, P.C., Yip, C.C., Li, K.S., Fu, C.T., Huang, Y., Chan, K.H., Yuen, K.Y., 2011. Coexistence of multiple strains of two novel porcine bocaviruses in the same pig, a previously undescribed phenomenon in members of the family Parvoviridae, and evidence for inter- and intra-host genetic diversity and recombination. J. Gen. Virol. 92, 2047-2059.

Li, B., Ma, J., Xiao, S., Fang, L., Zeng, S., Wen, L., Zhang, X., Ni, Y., Guo, R., Yu, Z., Zhou, J., Mao, A., Lv, L., Wang, X., He, K., 2012a. Complete genome sequence of a novel species of porcine bocavirus, PBoV5. J. Virol. 86, 1286-1287.

Li, B., Ma, J.J., Xiao, S.B., Zhang, X.H., Wen, L.B., Mao, L., Ni, Y.X., Guo, R.L., Zhou, J.M., Lv, L.X., He, K.W., 2012b. Development of a loop-mediated isothermal amplification method for rapid detection of porcine boca-like virus. J. Virol. Methods 179, 390-395.

Li, L., Shan, T., Wang, C., Cote, C., Kolman, J., Onions, D., Gulland, F.M., Delwart, E., 2011. The fecal viral flora of California sea lions. J. Virol. 85, 9909-9917. 
McKillen, J., McNeilly, F., Duffy, C., McMenamy, M., McNair, I., Hjertner, B., Millar, A., McKay, K., Lagan, P., Adair, B., Allan, G., 2011. Isolation in cell cultures and initial characterisation of two novel bocavirus species from swine in Northern Ireland. Vet. Microbiol. 152, 39-45.

Shan, T., Lan, D., Li, L., Wang, C., Cui, L., Zhang, W., Hua, X., Zhu, C., Zhao, W., Delwart, E., 2011a. Genomic characterization and high prevalence of bocaviruses in swine. PLoS One 6, e17292.

Shan, T., Li, L., Simmonds, P., Wang, C., Moeser, A., Delwart, E., 2011b. The fecal virome of pigs on a high-density farm. J. Virol. 85, 11697-11708.

Shi, M., Lam, T.T., Hon, C.C., Murtaugh, M.P., Davies, P.R., Hui, R.K., Li, J., Wong, L.T., Yip, C.W., Jiang, J.W., Leung, F.C., 2010. Phylogeny-based evolutionary, demographical, and geographical dissection of North American type 2 porcine reproductive and respiratory syndrome viruses. J. Virol. 84, 8700-8711.

Tamura, K., Peterson, D., Peterson, N., Stecher, G., Nei, M., Kumar, S., 2011. MEGA5: molecular evolutionary genetics analysis using maximum likelihood, evolutionary distance, and maximum parsimony methods. Mol. Biol. Evol. 28, 2731-2739.

Tijssen, P., Agbandje-McKenna, M., Almendral, J.M., Bergoin, M., Flegel, T.W., Hedman, K., Kleinschmidt, J., Li, Y., Pintel, D.J., Tattersall, P., 2011. Family parvoviridae. In: King, A.M.Q., Adams, M.J., Carstens, E.B., Lefkowitz, E.J. (Eds.), Virus Taxonomy. 9th Report of the International Committee on Taxonomy of Viruses. Academic Press, London, pp. 405-425.

Xiao, C.T., Halbur, P.G., Opriessnig, T., 2013. Molecular evolutionary genetic analysis of emerging parvoviruses identified in pigs. Infect. Genet. Evol.: J. Mol. Epidemiol. Evol. Genet. Infect. Dis. 16, 369-376.

Yang, W.Z., Yu, J.M., Li, J.S., Cheng, W.X., Huang, C.P., Duan, Z.J., 2012. Genome characterization of a novel porcine bocavirus. Arch. Virol. 157, 2125-2132.

Zeng, S., Wang, D., Fang, L., Ma, J., Song, T., Zhang, R., Chen, H., Xiao, S., 2011. Complete coding sequences and phylogenetic analysis of porcine bocavirus. J. Gen. Virol. $92,784-788$

Zhai, S., Yue, C., Wei, Z., Long, J., Ran, D., Lin, T., Deng, Y., Huang, L., Sun, L., Zheng, H., Gao, F., Chen, S., Yuan, S., 2010. High prevalence of a novel porcine bocavirus in weanling piglets with respiratory tract symptoms in China. Arch. Virol. 155, 1313-1317.

Zhang, H.B., Huang, L., Liu, Y.J., Lin, T., Sun, C.Q., Deng, Y., Wei, Z.Z., Cheung, A.K. Long, J.X., Yuan, S.S., 2011. Porcine bocaviruses: genetic analysis and prevalence in Chinese swine population. Epidemiol. Infect. 139, 1581-1586. 